\title{
Micromechanical Tests on Natural Fibre Composites with Enzymatically Enhanced Fibre-Matrix Adhesion
}

\author{
Hanna M. Brodowsky ${ }^{1,2}$ (D) Anne Hennig ${ }^{2,3}$ (D)
}

Received: 1 June 2021 / Revised: 31 July 2021 / Accepted: 5 October 2021 / Published online: 30 December 2021

(c) The Author(s) 2021

\begin{abstract}
Natural fibre-reinforced composites are more sustainable than other composites with respect to the raw materials. Their properties are attractive due to high specific properties, and especially so wherever high damping is valued. As the interphase between fibre and matrix is the region of highest stresses, a strong bond between fibre and matrix is essential for any composites' properties. The present study compares two methods of determining the interfacial shear stress in natural fibre-reinforced composites: the single fibre fragmentation test and the single fibre pullout test. The studied composites are flax fibre reinforced epoxy. For a variety of fibre-matrix interaction, the fibres are treated with a laccase enzyme and dopamine, which is known to improve the fibre-matrix shear strength. In the observed samples, single fibre fragmentation test data, i.e. of fracture mode and fragment length, scatter when compared to pullout data. In single fibre pullout tests, the local interfacial shear strength showed a $30 \%$ increase in the laccase-treated samples, compared to the control samples. The method also permitted an evaluation of the frictional stress occurring after surface failure.
\end{abstract}

Keywords Micromechanical testing $\cdot$ Interfacial shear strength $\cdot$ Natural fibre composite $\cdot$ Enzyme $\cdot$ Interface

\section{Introduction}

Plant fibres can be a sustainable alternative to replace glass fibres in composites. They combine acceptable mechanical properties with light weight, leading to high specific strength and modulus. Plant-based fibres used in high-quality reinforced polymer composites are usually bast fibres, obtained from, e.g. flax, jute or hemp. Considering specific strength and modulus, they are comparable to glass fibres (Bledzki and Gassan 1999). These fibres' load-bearing structure is made of cellulose fibrils. Amorphous hemicellulose and lignin interlink these structures. Flax typically contains $71 \%$

This article is part of the Topical Collection on Natural Fibers: Materials of the Future

Hanna M. Brodowsky

hanna.brodowsky@htwk-leipzig.de

1 HTWK, Leipzig University of Applied Sciences, Leipzig, Germany

2 Formerly: Leibniz-Institut Für Polymerforschung Dresden e.V. Dresden, Dresden, Germany

3 RWTH Aachen University, Aachen, Germany cellulose, 20\% hemicellulose and 2\% lignin (Bledzki et al. 1996; Ugbolue 1990).

In order for the fibres to bear the load applied to the composite, the stress needs to be transferred from the matrix to the reinforcing fibres. Therefore, the interphase between fibre and matrix is essential for a fibre-reinforced composite's properties (Kim and Mai 1998). The interphase is the region of the highest stress localisation, especially of shear stress. Manmade reinforcing fibres such as glass or carbon fibres are usually surface modified with a sizing in order to enhance the fibre-matrix adhesion and to improve processing (Mäder et al. 2001; Thomasson and Adzima 2001). These sizings are aqueous solutions of bi-functional coupling agents such as silanes, which form covalent bonds to both fibre and matrix. Other sizing components such as film formers aid in processing the fibres. In natural fibre composites, surface modifications are known to increase the mechanical properties of the composites (Bledzki et al. 1996; Bledzki and Gassan 1999; Pickering et al. 2007; Pickering et al. 2016; Xie et al. 2010). However, not many natural fibres are treated for better adhesion, perhaps because conventional fibre sizings are often not sustainable.

Several mechanical test methods such as compression shear test or peel test have been developed in order to test 
for the interfacial shear strength. Micromechanical tests on single fibre model composites are especially sensitive to shear stress (Kim and Mai 1998; Herrera-Franco and Drzal, 1992). In the field of natural fibre composites, some micromechanical tests have been reported (Li et al. 2009; Doan et al. 2012; Graupner et al. 2014; Thomason and RudeirosFernández 2021; Müssig and Graupner 2020). The present study compares two micromechanical tests and their use in natural fibre composites, namely the single fibre pullout test (SFPO) and single fibre fragmentation test (SFFT).

In order to compare the micromechanical methods, a set of samples were studied in which the fibres were treated with laccase for enhanced adhesion. Laccase (EC 1.10.3.2) is an enzyme found in fungi as well as plants, bacteria and animals. It is an oxidase specific for phenolic substrates. In a natural process known as whiterotting, the enzyme laccase degrades lignin in woody plant materials via oxidation (Kawai et al. 1988a, 1988b; Lundquist and Kristersson 1985). Laccase is derived from renewable, natural resources and is successfully being used in industrial processes, e.g. in the food, textile and paper industries (Minussi et al. 2002; Osma et al. 2010; Bajpai 1999; Camarero et al. 2004; Leonowicz et al. 2001), as well as for pollution control in water and soil (Abadulla et al. 2000; Blanquez et al. 2019; Claus et al. 2002; Kanagaraj et al. 2014; Kudanga et al. 2012). In Brodowsky et al. (2020), a sustainable modification for flax fibres is discussed with the aim of improving the interfacial shear strength in an epoxy matrix, using laccase as catalyst and dopamine as coupling agent. Dopamine is a phenolic derivative with an alkylamine substituent. Laccase modification is expected to (a) convert the phenolic moieties of dopamine to phenoxy radicals (Grönquist et al. 2006; Xiang et al. 2007) and (b) catalyse partial lignin oxidation, binding the dopamine to the fibre surface, where the amine moiety is free to react with the matrix, much like a silane in glass fibre-reinforced composites.

The focus of the present study is a comparison of two methods in determining the interfacial shear strength (IFSS) of natural fibre composites in micromechanical testing: SFFT and SFPO. The specimens are flax fibre epoxy micro-composites where the fibres are pretreated with a dopamine laccase solution in order to enhance fibre-matrix bonding.

\section{Materials and Methods}

\section{Materials}

Flax fibre yarn (250 tex) was obtained from Composites Evolution (Chesterfield, UK). Once the outer winding yarn was removed, it contained mostly single fibres of $2-6 \mathrm{~cm}$ length and $20 \mu \mathrm{m}$ diameter that could be used without further separation. Additionally, individual $4-\mathrm{cm}$ fibres cleaned in the Setralit ${ }^{\circledR}$ process were obtained from Setral Chemie (Germany). Dopamine hydrochloride of TraceCERT ${ }^{\circledR}$ grade was obtained from Sigma (St. Louis, MO, USA). Epoxy resin/hardener systems RIM 135/RIM 137 and $\mathrm{L}+\mathrm{L}$ were obtained from Hexion (Columbus, $\mathrm{OH}$, USA) and R\&G Faserverbundwerkstoffe GmbH (Waldenbuch, Germany) respectively.

Laccase enzyme from Cerrena unicolor fungus was kindly provided by the group of Bioprocess Engineering, Institute of Natural Materials Technology, Technical University Dresden, Germany. The fibre treatment was also performed by this group. Laccase and treatment are discussed in detail in Brodowsky et al. (2020).

Four different fibre treatments were compared:

- DL fibre treated with laccase enzyme in presence of its substrate dopamine in malonate buffer and three reference samples

- R fibre treated with the malonate buffer only

- RL fibre treated with laccase in buffer but without dopamine

- RD fibre treated with dopamine in buffer but without laccase

For an overview of the material-test-treatment combinations, cf. Table 1.

Table 1 Overview of materials, sample preparation and analysis methods

\begin{tabular}{|c|c|c|c|c|}
\hline Materials & Fibre treatment & Fibre characterisation & Micro-Composite & Micromechanical test \\
\hline \multirow[t]{2}{*}{$\begin{array}{l}\text { Flax fibre } \\
\text { Epoxy matrix }\end{array}$} & \multirow{2}{*}{$\begin{array}{l}\text { DL: } \\
\text { dopamine + laccase + buffer } \\
3 \text { references: } \\
\text { R: } \\
\text { neat buffer only } \\
\text { RL: } \\
\text { laccase + buffer } \\
\text { RD: } \\
\text { dopamine + buffer }\end{array}$} & \multirow{2}{*}{$\begin{array}{l}\text { Single fibre tensile test (R, RL) } \\
\text { SEM morphology (DL, R, RL, } \\
\text { RD) } \\
\text { For AFM morphology and col- } \\
\text { our analysis, cf. Brodowsky } \\
\text { et al. (2020) }\end{array}$} & $\begin{array}{l}\text { Single fibre along longitudi- } \\
\text { nal axis of micro-dumbbell } \\
\text { specimen, cf. Figure } 3 \mathrm{a}\end{array}$ & $\begin{array}{l}\text { Single fibre fragmentation test } \\
\quad(\mathrm{SFFT})(\mathrm{DL}, \mathrm{R}, \mathrm{RL}, \mathrm{RD}) \\
\text { - fracture modes } \\
\text { - fragment lengths }\end{array}$ \\
\hline & & & $\begin{array}{l}\text { Single fibre end embedded in } \\
\text { matrix droplet, cf. Figure } 7 \mathrm{a}\end{array}$ & $\begin{array}{l}\text { Single fibre pullout test (SFPO) } \\
\quad \text { (DL, R) } \\
-\tau_{\text {app }} \\
-\tau_{d}=\text { IFSS } \\
-\tau_{f} \\
-G_{i c}\end{array}$ \\
\hline
\end{tabular}




\section{Single Fibre Tensile Test}

The longitudinal tensile strength of single flax fibres was determined in a Favigraph single fibre tester (Textechno, Mönchengladbach, Germany). The fineness was determined vibrationally for each individual fibre. Consecutively, the single fibre's force elongation curve was measured. From this, Young's modulus ( 0.05 to $0.5 \%$ elongation) and strength were determined. The measurement was performed with 25 repetitions at $15 \mathrm{~mm} / \mathrm{min}$ with fibres clamped between vulcanite fasteners with 6 bar of pressure.

\section{Fibre Morphology}

The fibre surface was investigated by scanning electron microscopy (SEM) with the FE-SEM Ultra 55 microscope (Carl Zeiss SMT AG, Oberkochen, Germany) with an Everhart-Thornley detector. SEM was also used to determine the embedded length and the diameter of the fibre after pullout.

\section{Single Fibre Fragmentation Test (SFFT)}

Single flax fibres (Setralit@) were embedded in epoxy matrix $(\mathrm{L}+\mathrm{L}, \mathrm{R} \& \mathrm{G}$ Faserverbundwerkstoffe $\mathrm{GmbH}$, Waldenbuch, Germany), forming an approximately 1-mm-thick plate. The composites were cured at room temperature for $24 \mathrm{~h}$ and annealed at $60{ }^{\circ} \mathrm{C}$ for $10 \mathrm{~h}$. Dumbbell-shaped test specimens of $2 \mathrm{~cm}$ in length were cut with one single fibre oriented along the long axis. Longitudinal tensile tests up to specimen failure were performed on a Zwick Z2.5 universal testing machine at a crosshead speed of $0.2 \mathrm{~mm} / \mathrm{min}$ (ZwickRoell GmbH \& Co. KG, Ulm, Germany). The fibre breaks into several fragments before overall specimen failure occurs. Resulting fibre fractures were characterized by analysing polarized micrographs of the specimen after failure (Keyence VHX-2000). The number of fibre fragments, fragment lengths and fracture modes was studied on 16 micro-composites for each fibre modification type, each analysed over the gauge length of about $1 \mathrm{~cm}$.

\section{Single Fibre Pullout Test (SFPO)}

Single fibre micro-composites were produced and tested on devices developed and set up at the Leibniz Institute of Polymer Research Dresden, Germany (Mäder et al. 1994). A micro-composite was produced by embedding one end of a flax fibre into a droplet of epoxy matrix. Single fibres extracted from a Composites Evolution yarn and epoxy RIM 135/RIM137 (Hexion, Columbus, OH, USA) were used. The embedding length was preset to $100 \mu \mathrm{m}$. Micro-composites were cured for $60 \mathrm{~min}$ at $85^{\circ} \mathrm{C}$ in nitrogen atmosphere.

The vessel containing this micro-composite was clamped on an actuator. The fibre end protruding out of the matrix was glued onto a steel plate mandrel which was fixed to a force sensor. Force-displacement curves were obtained by quasistatically pulling the single fibre out of the matrix droplet.

After pullout, the fibre diameter and the embedding length (tip to meniscus) were checked for each fibre by SEM. Diameters were in the range of $d_{f}=20 \pm 5 \mu \mathrm{m}$, and the embedding lengths were in the range of $l_{e}=90 \pm 15 \mu \mathrm{m}$. Eight to 10 samples were studied for each modification. Only micro-composites with a complete pullout were analysed, that is samples where the fibre did not break above or within the matrix droplet during pullout, with identical criteria as those discussed in Brodowsky et al. (2020.) $n=7$ datasets for each fibre treatment type were analysed.

\section{Results and Discussion}

\section{Fibre Treatment and Characterization}

\section{Single Fibre Tensile Strength}

In wood-digesting fungus, the laccase enzymes' function is to break down the lignin in woody substance, usually in combination with cellulases digesting the cellulose. In the current application, the laccase is used for a pretreatment of reinforcing flax fibres, namely bonding the coupling agent dopamine to the fibre lignin. It is essential that the fibres' ability to bear loads is not compromised during the treatment. It would be feasible that the laccase reduces the strength, e.g. by oxidising the cellulose polymers or by disintegrating the fibre structure. To rule this out, the flax fibres were laccase-treated with an enzyme activity eight times that were used for dopamine binding experiments, and as a reference, fibres were treated in malonate buffer.

The Weibull distributions of the laccase-treated and buffer-treated control fibres are well comparable (Fig. 1). Even at a concentration eight times higher than in the final fibre modification, the laccase had no influence on the fibre fracture characteristics. The experiment was also repeated at higher treatment temperature, $50{ }^{\circ} \mathrm{C}$ as compared to $25^{\circ} \mathrm{C}$, that is at even increased enzyme activity, but nevertheless there is no fibre damage due to the laccase. The mean tensile strength is $400 \mathrm{MPa}$ for fibres modified at $25^{\circ} \mathrm{C}$ or $50{ }^{\circ} \mathrm{C}$, with no significant influence of the laccase. The fibre Young modulus is around $20 \mathrm{GPa}$ for fibres treated with neat buffer or laccase in buffer, for either treatment temperature, all changes lying within the error range of one standard deviation regardless of modification with buffer only or with laccase. In summary, no degradation of fibre properties was induced by the laccase treatment even under high activity conditions. 
Fig. 1 Weibull plot of single fibre tensile tests of buffer- and laccase-treated fibres ('25 U/ ml' laccase activity) and buffer only fibres (' $0 \mathrm{U} / \mathrm{ml}$ ') for $25^{\circ} \mathrm{C}$ and $50{ }^{\circ} \mathrm{C}$

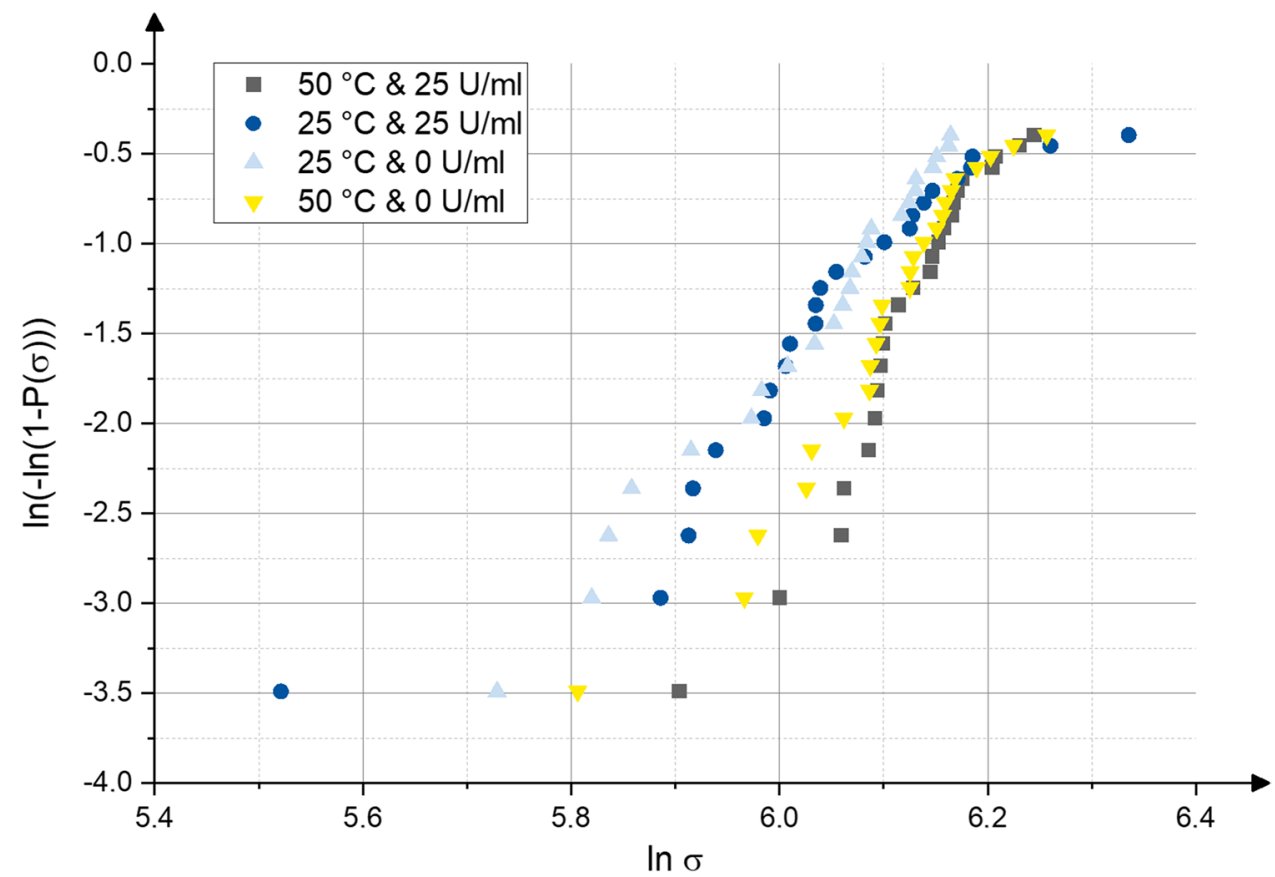

\section{Fibre Morphology}

Fibres were modified with laccase + dopamine in malonate buffer (DL) and as control samples in neat malonate buffer $(\mathrm{R})$, laccase in malonate (RL) or dopamine in malonate (RD). The four modified fibres were imaged with scanning electron microscopy (SEM). The different treatments led to different surface morphologies, and the micrographs are shown in Fig. 2. Similar to the results of Brodowsky et al.
(2020), the fibres exposed to neat malonate buffer or laccase (Fig. 2a: R, b: RL) had a smooth surface, compared to fibres treated with dopamine or laccase + dopamine (Fig. 2c: $\mathrm{RD}, \mathrm{d}: \mathrm{DL}$ ), where the surface is covered by a layer formed of $100 \mu \mathrm{m}$ flake structures, more pronounced in DL than in RD. In Brodowsky et al. (2020), the authors proposed to interpret the formed structures as a polydopamine layer. Dopamine can polymerise spontaneously in aqueous environment, forming polydopamine structures even in absence
Fig. 2 SEM micrographs of flax fibres: a R: buffer, $\mathbf{b}$ RL: buffer + laccase, $\mathbf{c}$ RD: buffer + dopamine and $\mathbf{d}$ DL: buffer + laccase + dopamine, after modification at $25^{\circ} \mathrm{C}$, scale bar $1 \mu \mathrm{m}$
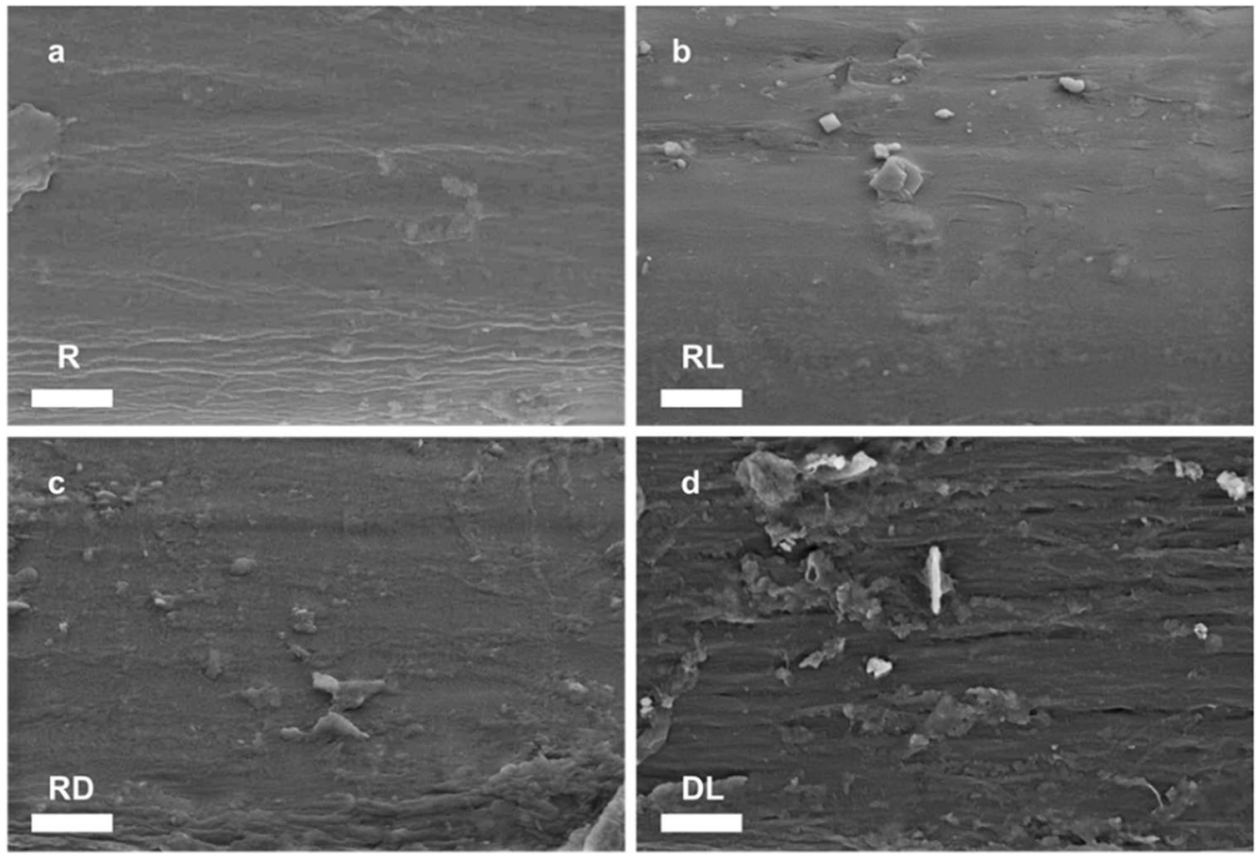
of laccase. Such a flaky layer surface morphology is also verified by atomic force microscopy images of DL-treated fibre as compared to the R fibre (Brodowsky et al. 2020).

\section{Single Fibre Fragmentation Tests (SFFT)}

Two different micromechanical tests are compared which quantify fibre-matrix adhesion strength in fibre-reinforced composites on single fibre model composites, namely SFFT and SFPO.

SFFT is a popular test of the shear strength in composites because it may be performed on standard testing equipment. A micro-composite with a single fibre embedded in a small dumbbell specimen is subjected to longitudinal stress. This stress is transferred to the interphase in the form of interfacial shear stress. As the tensile load increases, the stress exceeds the fibre's failure strain: the fibre will break into two fragments at the section's weakest position, assuming statistical fibre strength variations. The matrix will macroscopically remain intact at this point. The load is increased further, and the fibre will break into smaller and smaller fragments. At some point, the shear stress imposed on the fibre fragment surface can no longer exceed the fibre strength; the fragment has become too small to break further in this interfacial strength. The fibre fragmentation process is saturated, and the fragments have reached the so-called critical fibre length $l_{\mathrm{c}}$, presented also in Fig. $3 \mathrm{~b}$. Due to the statistical variations in fibre strength, a single fibre will break into fragments of unequal length. Smaller fragment length distributions correspond to higher interfacial strength (Tripathi and Jones 1998).

In order to produce specimen for the SFFT, several single laccase-treated fibres are fastened across a 2-cm-wide frame. This is filled with epoxy to create a plate containing parallel single fibres (Fig. 3a). After curing, the individual specimens are separated and cut into dumbbell shapes with the single fibre along the centre line of the composite (Fig. 3b).
Tensile tests in the fibre longitudinal direction are performed up to specimen failure. Resulting fibre fractures are characterized with transmission microscopy using a polarizing slide to reveal internal stress in the surrounding matrix through patterns in the polarized light. Fractures in fibre and matrix are visible as either (a) a darkened section of the fibre, as (b) a V- or X-shaped pattern of light in the matrix or else (c) a straight dark line in the matrix perpendicular to the fibre. These three fracture modes were differentiated by Drzal (1993), Asadi (2016) and Goswami (2019); the authors interpreted them as (a) debonding at the fibre surface within the composite, indicating weak adhesion; (b) a double cone crack with shear failure within the matrix, indicating intermediate adhesion; or (c) a disk crack where the matrix fails locally in a flat disk-like shape perpendicular to the fibre axis, indicating high adhesion, as matrix failure occurs before interface failure. Sixteen specimens were analysed over a gauge length of $1 \mathrm{~cm}$, for every fibre treatment (DL, $\mathrm{R}, \mathrm{RD}, \mathrm{RL}$ ), and fractures were classified according to Drzal 1993, as exemplified in Fig. 4. Additionally, die fibre fragment lengths for each specimen were analysed.

In a few specimens, the combined fragment length was clearly shorter than the $1 \mathrm{~cm}$ gauge length, due to unclear micrographs and fractures within the clamping area, so the distribution of fragment lengths could not be analysed. These specimens were excluded from further evaluations to ensure the correct distribution of fracture modes and fragment lengths.

In Fig. 5, the percentages for the three fracture modes are presented. The percentage of disk cracks, a straight crack through the matrix perpendicular to the fibre, is virtually independent of the treatment method, with an increase from $12 \%$ for $\mathrm{R}$ fibres to $15 \%$ for DL fibres. This corresponds to higher adhesion for RD- and DL-treated fibres toward epoxy. Regarding the percentages for double cone cracks and debonding, the DL fibres showed values comparable to $\mathrm{R}$ fibres; this unexpected finding would indicate comparable

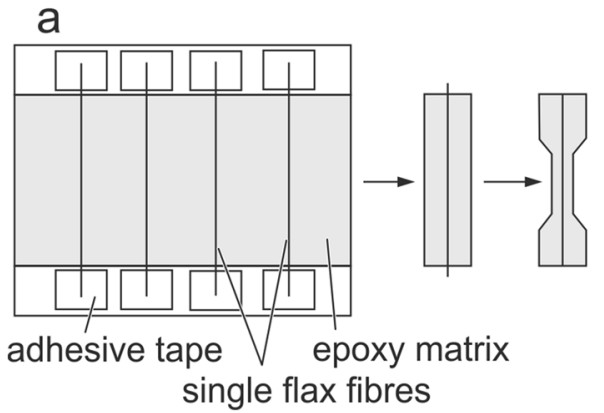

Fig. 3 SFFT. a Sample preparation. Single fibres are fastened by adhesive tape over a metal profile. After impregnation and curing of the epoxy, the individual specimens are cut into a dumbbell shape of $2 \mathrm{~cm}$ length with the single fibre along the centre line of the compos- b

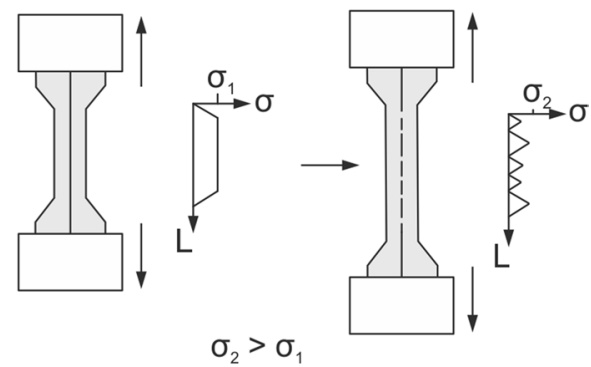

ite. b Tensile tests are performed on the resulting specimens: scheme of tests with respective stress distribution for fibres of different fragment lengths 
Fig. 4 Fracture modes: a disk crack indicating high adhesion, b double cone crack indicating intermediate adhesion and c debonding indicating weak adhesion, characterized according to Drzal (1993)
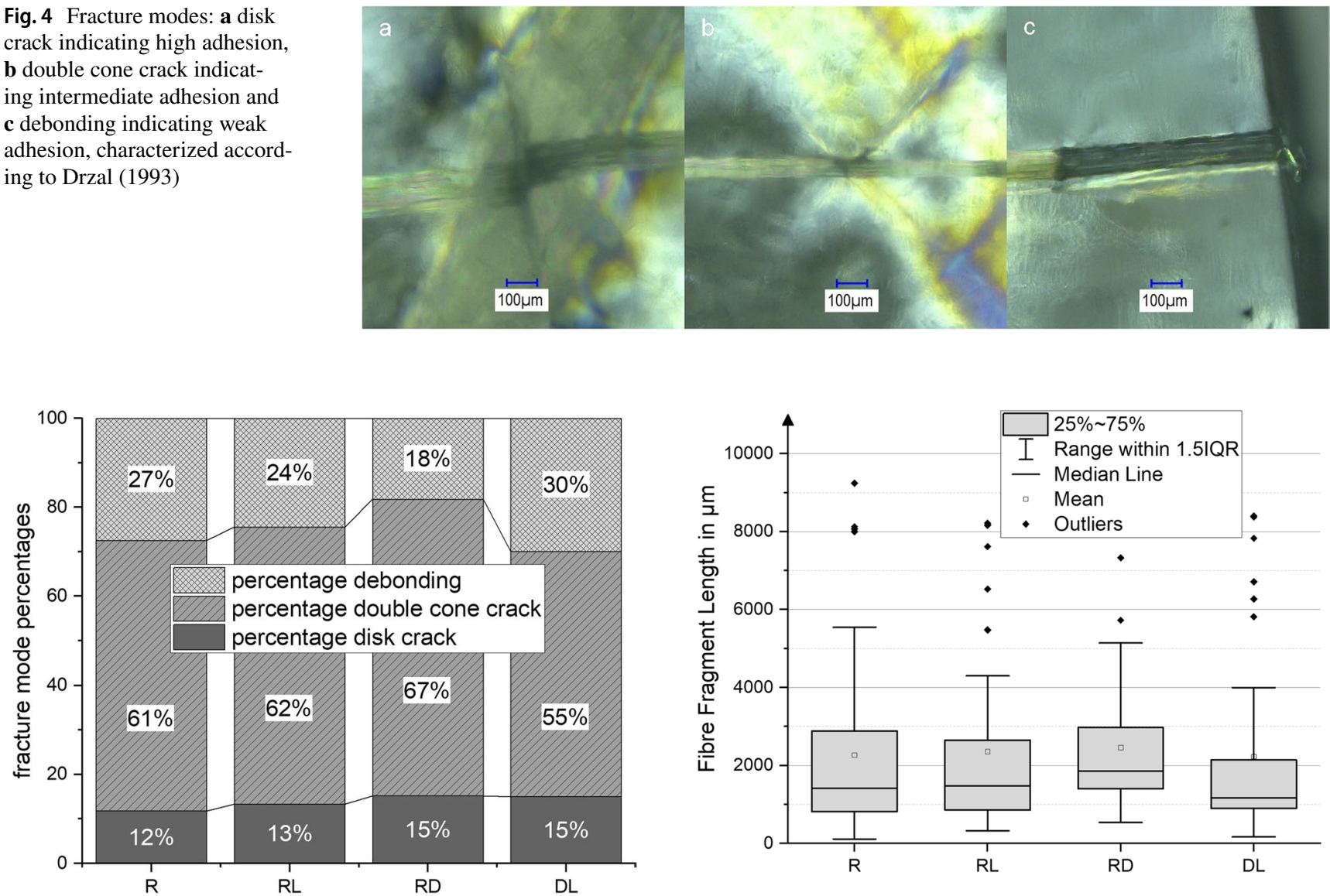

Fig. 5 Percentages for fracture modes for fibres treated with buffer only (R), buffer+laccase (RL), buffer+dopamine (RD) and buffer + laccase + dopamine (DL)

interfacial adhesion. For RD fibres, the percentage for double cone cracks is higher (67\%) compared to the $\mathrm{R}$ fibres $(61 \%)$ and the DL fibres (55\%). The percentage for debonding, assumed to be the clearest indicator for weak adhesion, is much lower (18\%) for RD than for RL and R (24\% and $27 \%$ respectively). Since dopamine can oxidize on its own, an effect as a coupling agent is possible, even without the catalysis by laccase. It should be noted, however, that the preceding classification of fracture modes is rather subjective and should therefore be regarded with caution.

For a more objective approach, the fibre fragment lengths were analysed for different fibre modifications. The boxplot in Fig. 6 shows the distribution of fragment lengths from the set of specimens with the same fibre treatment type. To ensure fibre fracturing before matrix failure, the elongation at break of the fibre should be at least 2.5 times lower than the matrix elongation. Due to the low elongation of the epoxy matrix in this study, the fragment lengths scatter. Despite the wide range of fragment

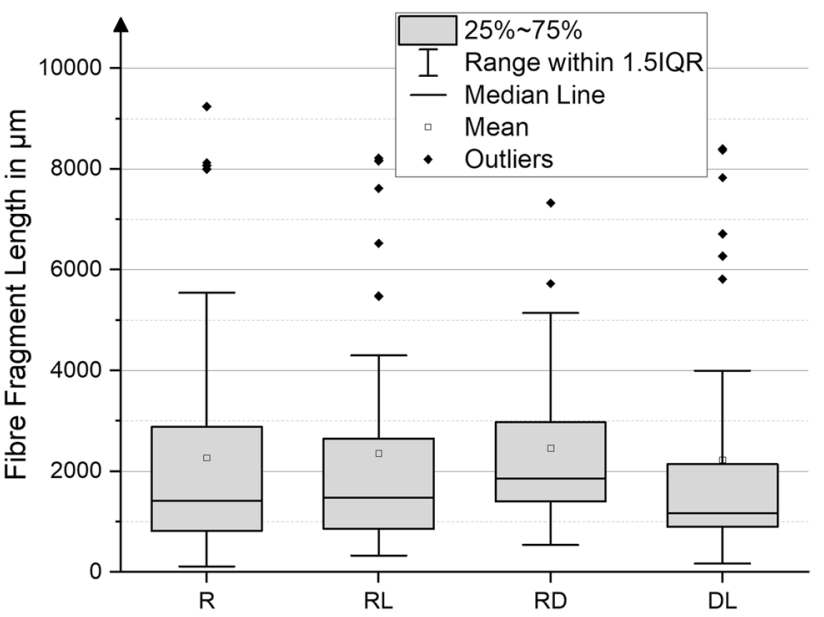

Fig. 6 Boxplot for fibre fragment length distributions after SFFT, for fibres treated with buffer only (R), buffer + laccase (RL), buffer + dopamine (RD) and buffer + laccase + dopamine (DL)

lengths, a tendency towards lower fragment lengths for DL fibres can be observed, with both the median and the interquartile range lower than $\mathrm{R}, \mathrm{RL}$ and $\mathrm{RD}$ reference specimens. Contrary to the result of the fracture mode evaluation, RD samples show higher median fragment lengths and an interquartile range at higher fragment lengths, indicating lower interphase adhesion.

Fragment lengths provided a more objective result, but are not in full accordance with the results of the fracture mode evaluation. In the present study, the SFFT is limited by a number of factors. The epoxy matrix was transparent, which is a prerequisite for visual detection in SFFT, but its elongation is limited. This limits the fibre fragmentation when the matrix fails. For a clean initial fibre surface, Setral-treated fibres were used. This is an ultrasound cleaning treatment which should remove the cement from the fibre surface. However, it might also have increased the flaw density on the fibre, leading to a higher scatter in fragment lengths. For comparison, the interfacial shear strength is determined by SFPO. 


\section{Single Fibre Pullout Tests (SFPO)}

Micro-composites for SFPO were made by embedding one end of a single fibre into a matrix droplet. These specimens were subjected to strain along the fibre axis: the fibre was quasistatically pulled out of the droplet (Fig. 7a). This test is a sensitive tool for interfacial shear strength.

Single fibre micro-composites were made on a specific embedding device: A droplet of liquid matrix was placed on the droplet support. The top section of a single fibre of $1 \mathrm{~cm}$ length was held in a vacuum device and the fibre lowered manually onto the matrix droplet, until the free end contacted the matrix surface. From this point, the fibre was inserted automatically into the matrix droplet up to the intended embedding length. The equipment is temperature controlled and may be flushed with nitrogen. The SFPO tests were performed on a device developed and set up at the IPF Dresden (Mäder et al. 1994). The droplet support is clamped onto the actuator; the protruding fibre is glued to a steel mandrel attached to a load cell. During the test, the fibre is longitudinally pulled out of the droplet while the force-displacement data are recorded. For a quasistatic experiment, the pullout is performed at $10 \mathrm{~nm} / \mathrm{s}$ during interphase fracture and $1 \mu \mathrm{m} / \mathrm{s}$ in the friction phase. The force is recorded as the displacement is increased. Forces between $1 \mathrm{mN}$ and $5 \mathrm{~N}$ can be detected.

In comparison to SFFT, SFPO permits quantitative measurements, the force-displacement curves are independent of qualitative optical analysis. Only micro-composites with DL fibres and control samples R were studied.

A generalized force-displacement curve of the pullout process of single fibre micro-composites is shown in Fig. 7b. During the initial linear elastic regime, the force-displacement curves rise steeply; here the micro-composite is undamaged. Interfacial failure starts with crack initiation at the surface of the micro-composite, at the so-called debond force. In the force-displacement curve, this is indicated by a more or less pronounced 'kink', an abrupt decrease in the slope. As the displacement along the micro-composite increases, the interfacial crack tip propagates slowly. At this stage of the force-displacement curve, part of the interphase is still intact and able to bear load, often at forces much higher than the debond force, up to or even beyond the force maximum. At the instability, the remaining interphase fails abruptly and full debonding occurs. For the remainder of the pullout curve, the force-displacement behaviour is determined by the frictional force between the fibre surface and the cylindrical tunnel of the matrix fracture surface, until the fibre is completely pulled out at the embedded length (Zhandarov and Mäder, 2014; Zhandarov et al. 2018, 2019).

In Fig. 8, two representative force-displacement curves for a buffer-treated $\mathrm{R}$ and for a buffer + laccase + dopamine DL-treated fibre are shown. These two fibres have comparable fibre diameters of $21 \mu \mathrm{m}$ and $19.4 \mu \mathrm{m}$ and embedded lengths of $91.5 \mu \mathrm{m}$ and $88.9 \mu \mathrm{m}$ respectively, for R and DL fibre. Generally, the force curves for the different samples vary in amplitude, in accordance with the pulled out fibres' diameter and embedded length. The step seen at $22 \mu \mathrm{m}$ is due to the change in pullout speed. The presented data were obtained at $10 \mathrm{~nm} / \mathrm{s}$ during interphase fracture and $1 \mu \mathrm{m} / \mathrm{s}$ in the friction phase. Overall, the fibre pullout curve shows the expected shape: a steep initial rise with a slight kink at crack initiation at $0.03 \mathrm{~N}$, a phase of controlled crack propagation up to the maximum force and a steep decline in force as the interphase fails fully. At $20 \%$ below maximum force, the

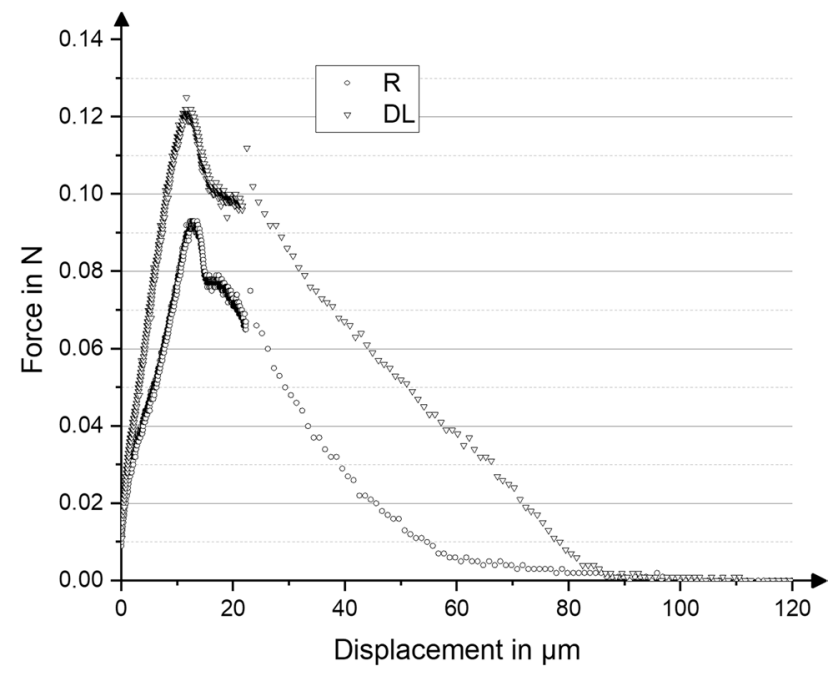

Fig. 8 SFPO: Force-displacement curves for one R and one DL fibre
Fig. 7 a Scheme of the pullout and $\mathbf{b}$ scheme of a force-displacement curve during pullout in analogy to Zhandarov et al. (2018a, 2018b) a

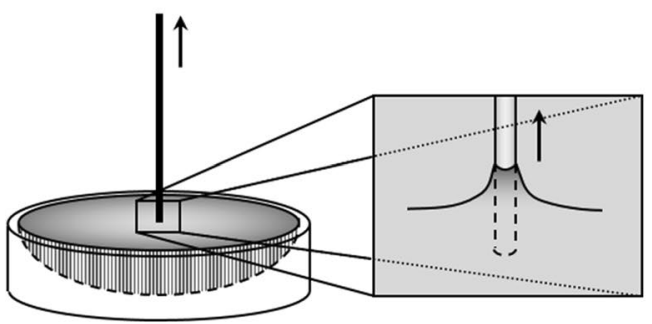

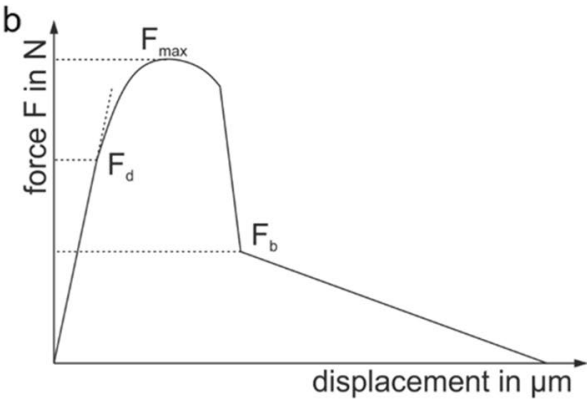


force curves stabilize and for the remainder of the curve the force is due to friction along the fibre mantle area as the fibre is pulled out of the tunnel. Note that the force reaches $0 \mathrm{~N}$ when the displacement reaches the embedding length around $90 \mu \mathrm{m}$. This coincides with the values mentioned above, which were determined tip-to-meniscus in SEM.

The force-displacement curves are evaluated for four different parameters (cf. Figure 9), namely (a) the apparent shear strength $\tau_{\text {app }}$, (b) the local interfacial shear strength IFSS or $\tau_{\mathrm{d}},(\mathrm{c})$ the interfacial frictional stress $\tau_{\mathrm{f}}$ and (d) the critical energy release rate $G_{\text {ic }}$. Each parameter has a specific perspective on the fracture behaviour.

The apparent shear strength (a) is calculated as $\tau_{\text {app }}=\frac{F_{\max }}{A}=\frac{F_{\max }}{\pi d_{\mathrm{f}} l_{\mathrm{e}}}$ where $A=\pi d_{\mathrm{f}} l_{\mathrm{e}}$ is the embedded mantle area. It describes the maximum load the interphase is able to bear. Many micromechanical measurements of the IFSS using pullout or microbond test determine only $\tau_{\text {app }}$, as it is the most easily determined parameter. In determining the apparent IFSS $\tau_{\text {app }}$, one assumes a constant shear stress at the fibre-matrix interface. In reality, non-linear shear stress occurs near the fibre ends (Kim and Mai 1998). $\tau_{\text {app }}$, values can only be compared for a set of micro-composites with the same embedding lengths. The apparent shear strength values observed on the flax epoxy micro-composites are $\tau_{\text {app }}=$ $34 \pm 6 \mathrm{MPa}$ for the DL micro-composite compared to $\tau_{\mathrm{app}}=$ $24 \pm 6 \mathrm{MPa}$ for the R micro-composite (Fig. 9a), i.e. the $\tau_{\text {app }}$ increases by $30 \%$. This is in accordance with the fragment length analysis of the SFFT, where qualitative results indicate a higher shear strength in the treated fibre samples.

The more relevant parameter is the local IFSS or $\tau_{\mathrm{d}}$, determined locally at the tip of a crack which is initiated where the fibre enters the matrix droplet and propagates along the fibre (Pisanova et al., 2001). $\tau_{\mathrm{d}}$ may be determined from the complete force-displacement dataset, that is based on the crack propagation process, as proposed by Zhandarov and Mäder (2014) and Zhandarov et al. (2018). In Fig. 9b, this evaluation of IFSS is compared to a calculation using a model focusing on the debond force $F_{\mathrm{d}}$, the maximum interfacial stress at initial crack formation (Zhandarov and Mäder, 2014), i.e. the position of the kink. For DL-treated fibres, the local IFSS $\tau_{\mathrm{d}}$ increases by about $30 \%$ from $38 \pm 8$ to $50 \pm 10 \mathrm{MPa}$ (Fig. 9b, dark boxes). When the calculations based on the determination of the debond force are used, the scatter is higher: DL micro-composites: $(50 \pm 10) \mathrm{MPa}$ vs. R micro-composites: $(40 \pm 15) \mathrm{MPa}$; the distributions are wider, and median and mean differ much more (Fig. 9b, white boxes). The latter determination depends critically on the precise determination of the kink in the force-displacement curve. Many data sets show a curve rather than a clear kink, so the debond force or force of crack initiation is often not well defined.

Another interfacial parameter, (c) the interfacial frictional stress, $\tau_{\mathrm{f}}$, describes the interfacial frictional shear force after the surface has failed. $\tau_{\mathrm{f}}$ also increased by $35 \%$ from $20 \pm 6$ to $27 \pm 6 \mathrm{MPa}$ (Fig. 9c). The parameter is determined by interfacial adhesion and friction between fibre and matrix
Fig. 9 Boxplot of interfacial shear parameters. a Apparent interfacial shear strength $\left(\tau_{\text {app }}\right)$. b Local interfacial shear strength $\left(\tau_{\mathrm{d}}\right)$, calculated from the force-displacement curves by two different methods: dark boxes-parameters determined from the overall shape of the force-displacement curve, white boxes-determined from debond force. $\mathbf{c}$ Interfacial frictional stress $\left(\tau_{\mathrm{f}}\right)$. d Critical energy release rate $G_{\text {ic }}$
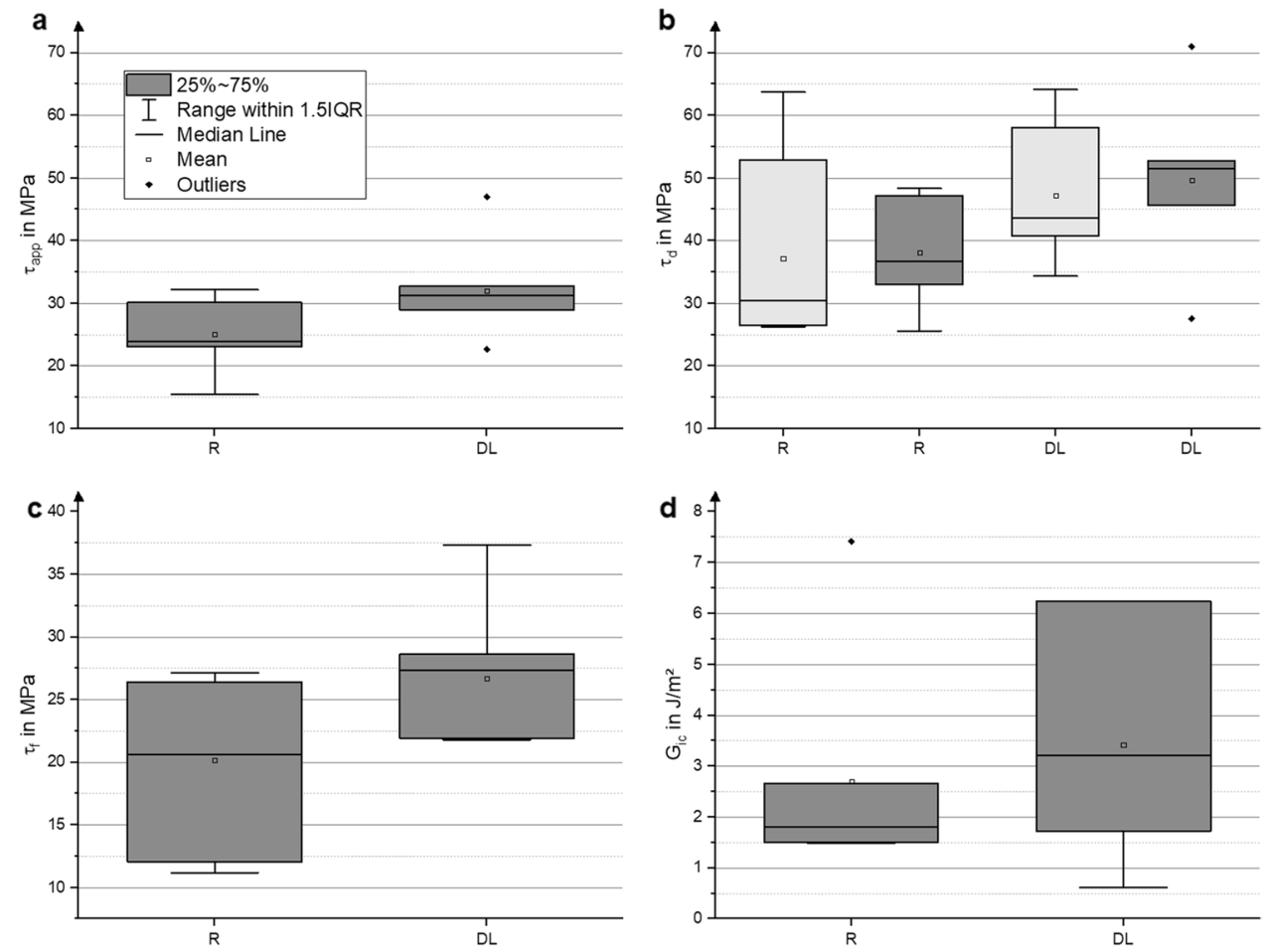
that is due to attractive molecular forces, not bonding, and due to the roughness of the interface after failure.

The fourth interfacial parameter (d), the critical energy release rate $G_{\text {ic }}$, also increases, from $2.7 \pm 2$ to $3.4 \pm 2 \mathrm{~J} / \mathrm{m}^{2}$ (cf. Figure 9d). Here, the method cannot quantify the difference between the interfacial bonding significantly due to large scatter.

\section{Comparison of SFFT and SFPO for the Analysis on Natural Fibre Composites}

When applying micromechanical tests in order to study interfacial adhesion, a direct comparison of characteristic values is only possible within a test series in which exactly the same methods are used for preparation, testing and evaluation (Müssig and Graupner 2020). Tests on natural fibre composites add some specific issues due to the characteristics of natural fibres. The concept of single fibres is different than in synthetic fibres. A single fibre is basically one dried plant cell (Müssig and Graupner 2020). It is limited in length, often to $1 \mathrm{~cm}$ or less, with pointed tips. In micromechanical tests, the fibre circumference is an essential parameter. Natural fibre cross-sections are often not circular but flattened, polygonal or even kidney shaped (Thomason et al. 2011). In the present case, the fibres were of circular diameters (cf. Figure 2). Often, natural fibres' diameters scatter within one yarn sample. Single natural fibres are often curved, adding an extra step to the embedding process (Thomason 2021). Micromechanical measurements are often made on fibre bundles. These are made up of a small number of single fibres that are bound together by lignin. The cross-section is irregular, making it difficult to determine the circumference, needed to calculate the IFSS. Bundles may come apart after treatment, exposing sections of untreated surface, and they fail by splintering lengthwise. All this needs to be taken into consideration in addition to what is necessary for all micromechanical experiments. On the other hand, micromechanics experiments provide insight into the interfacial parameters not readily accessible otherwise. They use little material, which permits early-stage experimental studies.

SFFT can be performed on standard mechanical testing equipment. Micro-composite preparation is comparatively easy (Awal et al., 2011). The matrix needs to be transparent if visual analysis is performed. If the matrix has a low elongation before break, the composite fails before fibre fragments are broken down to the critical length $l_{\mathrm{c}}$ (Kim and Mai, 1998). Quantitative analysis of the shear strength is possible if fibre circumferences and fibre strength are known. In natural fibres, they need to be determined for each single fibre, e.g. after failure. In this SFFT study, the fracture mode and fragment length analysis were performed. The fracture mode analysis was not fully consistent with the differences in adhesion strength. The fragment lengths could be evaluated qualitatively: A shorter fibre distribution indicates that the DL treatment improves the interfacial shear strength.

For SFPO, specially built equipment is needed (Kim and Mai, 1998); several geometries have been realised (for an overview, cf. Müssig 2020). Commercial testing equipment is available. Embedding the end of a natural fibre into a matrix droplet is tricky, especially if the matrix viscosity is high and if the fibre is not stiff and straight. The SFPO as has been used here provides quantitative data of the interfacial shear parameters. The apparent shear strength is the parameter most often determined (Müssig and Graupner, 2020). It is based on the simplification that there is a constant shear stress at the fibre-matrix interface, and will therefore depend on the embedding length. In reality, non-linear shear stress occurs at the regions near the fibre ends (Kim and Mai 1998). The local interfacial shear strength, IFSS or $\tau_{d}$, determined at maximum interfacial stress near the tip of a crack which is propagating along the fibre determines a parameter independent of geometry.

\section{Conclusions}

Natural fibre composites have a high potential as sustainable alternative to conventional composites. There is an ongoing search for sustainable surface treatments in order to improve the fibre-matrix bonding for these composites. In order to quantify the interfacial bonding, existing micromechanical methods characterizing the interphase must be transferred to natural fibre composites. By analysing single fibre model composites, they permit insight into the interphase, ignoring several composite effects such as fibre-fibre interactions or layer effects, while also only needing small amounts of material.

In the present study, the SFFT provides qualitative data on conventional testing equipment and with comparable ease. The SFPO test provides more quantitative results than the SFFT on this flax fibre model epoxy composite. In order to determine local interfacial parameters, a detailed quantitative analysis has been applied here. The local interfacial shear strength $\tau_{\mathrm{d}}$ and interfacial frictional stress $\tau_{\mathrm{f}}$ could be determined. The critical energy release rate $G_{\text {ic }}$ has a high error and cannot be considered in the present case. Using micromechanical tests is even more tedious than for composites of synthetic fibres, but it is possible, and in the present case provided valuable results.

Flax fibres were treated with the enzyme laccase, to covalently bond dopamine as a coupling agent using partial lignin degradation reactions. The fibre treatment improved the fibre-matrix interaction, increasing the interfacial shear strength by $30 \%$. This is promising; the work will be continued, and an upscaling using industrially produced laccase 
is planned in order to produce macroscopic composites for conventional mechanical tests, again focussing on the interphase. A laccase-based interface modification should also be applicable to other coupling agents, specifically ones where a strong interfacial bond is expected towards matrices other than epoxy, opening a sustainable technique for tailoring interfaces for a wide variety of matrices.

Acknowledgements The authors would like to thank A. Werner, Technical University Dresden, Germany, for performing the laccase treatment of the fibres; S. Preßler and A. Rothe, Leibniz Institut für Polymerforschung Dresden e.V. IPF Dresden, Germany, for performing the single fibre tensile tests, single fibre pullout tests and SEM measurements; S. Zhandarov, Academy of Sciences of Belarus, Belarus, for calculating the interfacial shear strengths; N Schneider, IPF Dresden, Germany, for preparing the composite specimens for the single fibre fragmentation tests; and O. Bendlin, RWTH Aachen, Germany, for analysis of the single fibre fragmentation micrographs.

Author Contribution HMB: conceptualisation, methodology, preparation, investigation, data curation, formal analysis, writing.

A.H: methodology, preparation, investigation, data curation, formal analysis, visualisation, writing.

All authors have read and agreed to the published version of the manuscript.

Funding Open Access funding enabled and organized by Projekt DEAL.

Data Availability The datasets generated and/or analysed during the current study are available from the corresponding author on reasonable request.

\section{Declarations}

Conflict of Interest The authors declare no competing interests.

Open Access This article is licensed under a Creative Commons Attribution 4.0 International License, which permits use, sharing, adaptation, distribution and reproduction in any medium or format, as long as you give appropriate credit to the original author(s) and the source, provide a link to the Creative Commons licence, and indicate if changes were made. The images or other third party material in this article are included in the article's Creative Commons licence, unless indicated otherwise in a credit line to the material. If material is not included in the article's Creative Commons licence and your intended use is not permitted by statutory regulation or exceeds the permitted use, you will need to obtain permission directly from the copyright holder. To view a copy of this licence, visit http://creativecommons.org/licenses/by/4.0/.

\section{References}

Abadulla E, Robra K-H, Gübitz GM, Silva LM, Cavaco-Paulo A (2000) Enzymatic decolorization of textile dyeing effluents. Text Res J 70:409-414. https://doi.org/10.1177/004051750007000506

Asadi A, Miller M, Moon RJ, Kalaitzidou K (2016) Improving the interfacial and mechanical properties of short glass fiber/epoxy composites by coating the glass fibers with cellulose nanocrystals.
EXPRESS Polymer Letters 10(7):587-597. https://doi.org/10. 3144/expresspolymlett.2016.54

Awal A, Cescutti G, Ghosh SB, Müssig J (2011) Interfacial studies if natural fibre/polypropylene composites using single fibre fragmentation test (SFFT). Compos Part A Appl Sci Manuf 42:50-56. https://doi.org/10.1016/j.compositesa.2010.10.007

Bajpai P (1999) Application of enzymes in the pulp and paper industry. Biotechnol Progr 15:147-157. https://doi.org/10.1021/bp990013k

Blanquez A, Rodriguez J, Brissos V, Mendes S, Martins LO, Ball AS, Arias ME, Hernandez M (2019) Decolorization and detoxification of textile dyes using a versatile Streptomyces laccase-natural mediator system. Saudi J Biol Sci 26:913-920. https://doi.org/10. 1016/j.sjbs.2018.05.020

Bledzki AK, Gassan J (1999) Composites reinforced with cellulose based fibres. Prog Polym Sci 24:221-274. https://doi.org/10.1016/ S0079-6700(98)00018-5

Bledzki AK, Reihmane S, Gassan J (1996) Properties and modification methods for vegetable fibers for natural fibre composites. J Appl Polym Sci 59:1329-1336. https://doi.org/10.1002/(SICI) 1097-4628(19960222)59:8\%3C1329::AID-APP17\%3E3.0. $\mathrm{CO} ; 2-0$

Brodowsky HM, Hennig A, Müller MT, Werner A, Zhandarov S, Gohs U (2020) Laccase-enzyme treated flax fibre for use in natural fibre epoxy composites. Materials 13:4529. https://doi.org/10.3390/ ma13204529

Camarero S, Garcia O, Vidal T, Colom J, del Rio JC, Gutierrez A, Gras JM, Monje R, Martinez MJ, Martinez AT (2004) Efficient bleaching of non-wood high-quality paper pulp using laccase-Thomason et al.mediator system. Enzyme Microbial Technol 35:113-120. https://doi.org/10.1016/j.enzmictec.2003.10.019

Claus H, Faber G, Konig H (2002) Redox-mediated decolorization of synthetic dyes by fungal laccases. Appl Microbiol Biotechnol 59:672-678. https://doi.org/10.1007/s00253-002-1047-z

Doan T-T-L, Brodowsky HM, Mäder E (2012) Jute fibre/epoxy composites: surface properties and interfacial adhesion. Compos Sci Technol 72:1160-1166. https://doi.org/10.1016/j.compscitech. 2012.03.025

Dong A, Wu H, Fan X, Wang Q, Yu Y, Cavaco-Paulo A (2016) Enzymatic hydrophobization of jute fabrics and its effect on the mechanical and interfacial properties of jute/PP composites. Express Polym Lett 10:420-429. https://doi.org/10.3144/expre sspolymlett.2016.39

Dong A, Yu Y, Yuan J, Wang Q, Fan X (2014) Hydrophobic modification of jute fiber used for composite reinforcement via laccasemediated grafting. Appl Surf Sci 301:418-427. https://doi.org/10. 1016/j.apsusc.2014.02.092

Goswami J, Haque E, Fox DM, Gilman JW, Holmes GA, Moon RJ, Kalaitzidou K (1951) The effect of cellulose nanocrystal coatings on the glass fibre-epoxy interphase. Materials 2019:12. https://doi. org/10.3390/ma12121951

Graupner N, Rößler J, Ziegmann G, Müssig J (2014) Fibre/matrix adhesion of cellulose fibres in PLA, PP and MAPP: a critical review of pull-out test, microbond test and single fibre fragmentation test results. Compos. Part A Appl Sci Manuf 63:133-148. https://doi.org/10.1016/j.compositesa.2014.04.011

Grönqvist S, Rantanen K, Alen R, Mattinen M-L, Buchert J, Viikari L (2006) Laccase-catalysed functionalisation of TMP with tyramine. Holzforschung 60:503-508. https://doi.org/10.1515/HF.2006.083

Herrera-Franco PJ, Drzal LT (1992) Comparison of methods for the measurement of fibre/matrix adhesion in composites. Compos 23:2-27. https://doi.org/10.1016/0010-4361(92)90282-Y

Kanagaraj J, Senthilvelan T, Panda RC (2014) Degradation of azo dyes by laccase: biological method to reduce pollution in dye wastewater. Clean Technol Environ Policy 17:1443-1456. https://doi.org/ 10.1007/s10098-014-0869-6 
Kawai S, Umezawa T, Higuchi T (1988a) Degradation mechanisms of phenolic $\beta-1$ lignin substructure model compounds by laccase of Coriolus versicolor. Arch Biochem Biophys 262:99-110. https:// doi.org/10.1016/0003-9861(88)90172-5

Kawai S, Umezawa T, Shimada M, Higuchi T (1988b) Aromatic ring cleavage of 4,6-di(tert-butyl) guaiacol, a phenolic lignin model compound, by laccase of Coriolus versicolor. FEBS Lett 236:309311. https://doi.org/10.1016/0014-5793(88)80043-7

Kim J-K, Mai Y-W (1998) Engineered interfaces in fibre reinforced composites. Elsevier Publishers, Oxford, UK

Kudanga T, Burton S, Nyanhongo GS, Guebitz GM (2012) Versatility of oxireductases in the remediation of environmental pollutants. Front Biosci 4:1127-1149. https://doi.org/10.2741/e446

Kudanga T, Nyanhongo GS, Guebitz GM, Burton S (2011) Potential applications of laccase-mediated coupling and grafting reactions: a review. Enzyme Microb Technol 48:195-208. https://doi.org/10. 1016/j.enzmictec.2010.11.007

Kudanga T, Prasetyo EN, Sipilä J, Guebitz GM, Nyanhongo GS (2010) Reactivity of long chain alkylamines to lignin moieties: implications on hydrophobicity of lignocellulose materials. J Biotechnol 149:81-87. https://doi.org/10.1016/j.jbiotec.2010.06.020

Leonowicz A, Cho N-S, Luterek J, Wilkolazka A, Wojtas-Wasilewska M, Matuszewska A, Hofrichter M, Wesenberg D, Rogalski J (2001) Fungal laccase: properties and activity on lignin. J Basic Microbiol 41:185-227. https://doi.org/10.1002/15214028(200107)41:3/4\%3C185::AID-JOBM185\%3E3.0.CO;2-T

Li F, Yu Y, Wang Q, Yuan J, Wang P, Fan X (2018) Polymerization of dopamine catalyzed by laccase: comparison of enzymatic and conventional methods. Enzyme Microb Technol 119:58-64. https:// doi.org/10.1016/j.enzmictec.2018.09.003

Li Y, Pickering KL, Farrell RL (2009) Determination of interfacial shear strength of white rot fungi treated hemp fibre reinforced polypropylene. Compos Sci Technol 69:1165-1171. https://doi. org/10.1016/j.compscitech.2009.02.018

Lundquist K, Kristersson P (1985) Exhaustive laccase-catalysed oxidation of a lignin model compound (vanillyl glycol) produces methanol and polymeric quinoid products. Biochem J 229:277-279. https://doi.org/10.1042/bj2290277

Mäder E, Grundke K, Jacobasch H-J, Wachinger G (1994) Surface, interphase and composite property relations in fibre-reinforced polymers. Composites 25:739-744. https://doi.org/10.1016/00104361(94)90209-7

Mäder E, Moos E, Karger-Kocsis J (2001) Role of film formers in glass fibre reinforced polypropylene-new insights and relation to mechanical properties. Compos Part A Appl Sci Manuf 32:631639. https://doi.org/10.1016/S1359-835X(00)00156-1

Minussi RC, Pastore GM, Durán N (2002) Potential applications of laccase in the food industry. Trends Food Sci Technol 13:205-216. https://doi.org/10.1016/S0924-2244(02)00155-3

Müssig J, Graupner N (2020) Test methods for fibre/matrix adhesion in cellulose fibre-reinforced thermoplastic composite materials: a critical review. Reviews of Adhesion and Adhesives 8:68-129. https://doi.org/10.7569/RAA.2020.097306

Osma JF, Toca-Herrera JL, Rodríguez-Couto S (2010) Uses of laccases in the food industry. Enzyme Res 2010:1-8. https://doi.org/10. 4061/2010/918761

Pickering KL, Beckermann GW, Alam SN, Foreman NJ (2007) Optimising industrial hemp fibre for composites. Compos Part a: Appl Sci Manuf 38:461-468. https://doi.org/10.1016/j.compositesa. 2006.02.020
Pickering KL, Efendy MGA, Le TM (2016) A review of recent developments in natural fibre composites and their mechanical performance. Compos Part A Appl Sci Manuf 83:98-112. https://doi. org/10.1016/j.compositesa.2015.08.038

Pisanova E, Zhandarov S, Mäder E, Ahmad I, Young RJ (2001) Three techniques of interfacial bond strength estimation from direct observation of crack initiation and propagation in polymer-fibre systems. Compos Part A Appl Sci Manuf 32:435-443. https://doi. org/10.1016/S1359-835X(00)00054-3

Thomason JL, Adzima LJ (2001) Sizing up the interphase: an insider's guide to the science of sizing. Compos Part a: Appl Sci Manuf 32:313-321. https://doi.org/10.1016/S1359-835X(00)00124-X

Thomason JL, Carruthers J, Kelly J, Johnson G (2011) Fibre cross-section determination and variability in sisal and flax and its effects on fibre performance characterisation, Comp.Sci.Technol, 71, https://doi.org/10.1016/j.compscitech.2011.03.007

Thomason JL, Rudeiros-Fernández JL (2021) Characterization of interfacial strength in natural fibre - polyolefin composites at different temperatures. Comp Interf. https://doi.org/10.1080/09276 440.2021.1913901

Tripathi D, Jones FR (1998) Single fibre fragmentation test for assessing adhesion in fibre reinforced composites. Journal of Materials Science, 33, 1-16 https://doi.org/10.1023/A:1004351606897

Ugbolue SCO (1990) Structure/property relationships in textile fibres. Text Prog 20:1-43. https://doi.org/10.1080/00405169008688950

Xie Y, Hill CAS, Xiao X, Militz H, Mai C (2010) Silane coupling agents used for natural fiber/polymer composites: a review. Comp Part a: Appl Sci Manuf 41:806-819. https://doi.org/10.1016/j. compositesa.2010.03.005

Xiang L, Lin Y, Yu P, Su L, Mao L (2007) Laccase-catalyzed oxidation and intramolecular cyclization of dopamine: a new method for selective determination of dopamine with laccase/carbon nanotube-based electrochemical biosensors. Electrochim Acta 52:4144-4152. https://doi.org/10.1016/j.electacta.2006.11.040

Zhandarov S, Mäder E (2014) An alternative method of determining the local interfacial shear strength from force-displacement curves in the pull-out and microbond tests. Int J Adhes Adhes 55:37-42. https://doi.org/10.1016/j.ijadhadh.2014.07.006

Zhandarov S, Mäder E, Gohs U (2018) Why should the "alternative" method of estimating local interfacial shear strength in a pull-out test be preferred to other methods? Materials, 11, https://doi.org/ 10.3390/ma11122406

Zhandarov S, Mäder E, Scheffler C, Kalinka G, Poitzsch C, Fliescher S (2018b) Investigation of interfacial strength parameters in polymer matrix composites: compatibility and reproducibility. Advanced Industrial and Engineering Polymer Research 1(1):82-92. https:// doi.org/10.1016/j.aiepr.2018.06.002

Zhandarov S, Scheffler C, Mäder E, Gohs U (2019) Three specimen geometries and three methods of data evaluation in single-fiber pullout tests. Mech Compos Mater 55:69-84. https://doi.org/10. 1007/s11029-019-09793-1

Publisher's Note Springer Nature remains neutral with regard to jurisdictional claims in published maps and institutional affiliations. 